\title{
Causality and Pleiotropy in the Association Between Bullying Victimization in Adolescence and Depressive Episodes in Adulthood
}

\author{
Tina Kretschmer, ${ }^{1}{ }^{*} *$ Felix C. Tropf, ${ }^{2}{ }^{*}$ and Nynke M. D. Niezink ${ }^{3}$ \\ ${ }^{1}$ Department of Pedagogy and Educational Science, University of Groningen, Groningen, the Netherlands \\ ${ }^{2}$ Department of Sociology/Nuffield College, University of Oxford, Oxford, UK \\ ${ }^{3}$ Department of Sociology, University of Groningen, Groningen, the Netherlands
}

\begin{abstract}
Children and adolescents who are victims or perpetrators of bullying victimization are at elevated risk for maladjustment problems, concurrently and in the long run. Previous studies suggest that this correlation is partly explained by genetic influence. However, whether the genetic correlation is independent of a causal effect of victimization on maladjustment remains unclear. Using data from 2,510 females from the TwinsUK registry, we applied an innovative extension of the Cholesky decomposition to investigate to what extent the association between victimization in adolescence and self-reported depressive episodes in adulthood is caused by shared genetic effects (pleiotropy), and to what extent it is due to a phenotypic causal relationship. We find that around $60 \%$ of the association between victimization and self-reported depressive episodes is due to a causal effect of victimization on depressive episodes, and $40 \%$ is due to pleiotropic effects. These findings underline the importance of integrating genetic information into social science research and demonstrate a neat strategy to elucidate causal mechanisms in the absence of experimental designs.
\end{abstract}

- Keywords: bullying victimization, depression, twin study, within-MZ twin, TwinsUK, ACE- $\beta$ model

Bullying victimization is commonly defined as overt or covert aggression within a power-imbalanced relationship and includes frequent name calling, social exclusion, taking away or destroying someone's belongings, and subjecting others to physical attacks and verbal insults (Olweus, 1993). Depending on study context and reporter, between $10 \%$ and $40 \%$ of children and adolescents are affected by bullying as perpetrators or victims, or both (Nansel et al., 2001; Schreier et al., 2009). Victims, in particular, are at elevated risk for a range of maladjustment problems, both in the short and in the long run (Copeland et al., 2013; Kretschmer et al., 2014; Wolke et al., 2013). In fact, victimized individuals show problems in a range of domains up into middle adulthood, as shown by studies utilizing longrunning birth cohorts (Takizawa et al., 2014).

It is not fully established, however, to what extent peer victimization constitutes an independent risk for maladjustment, as underlying genetic or family environment factors might explain (part of) the association between peer victimization and the maladjustment. So far, most genetically sensitive studies on this topic employed child samples and focused on concurrent or temporally proximal maladjustment (Arseneault et al., 2008; Brendgen et al., 2009; Brendgen et al., 2015; Shakoor et al., 2015; Singham et al., 2017). The majority of those studies did not explicitly study causality but focused on disentangling genetic and environmental contributions to covariance between exposure to victimization and maladjustment. Responding to these limitations, we employed an innovative modeling strategy that proposes to establish statistical causality between peer victimization and maladjustment and to simultaneously examine the role of latent family influences as common sources for this relationship.

RECEIVEd 29 November 2017; ACCEPTEd 4 December 2017

ADDRESS FOR CORRESPONDENCE: Tina Kretschmer, Department of Pedagogy and Educational Science, Faculty of Behavioural and Social Sciences, University of Groningen, Grote Rozenstraat 38, 9712 TJ Groningen, the Netherlands. E-mail: t.kretschmer@rug.nl

${ }^{*}$ TK and FCT contributed equally to the manuscript and share first authorship. 


\section{Genetic and Environmental Sources of Variance in Peer Victimization}

Genetically informed studies suggest that individual differences in peer victimization are partly heritable, although estimates vary greatly. Using the Environmental Risk (ERisk) Longitudinal Study sample of over 1,100 child and mother reports of victimization, Ball and colleagues (2008) reported that $73 \%$ of the variance in victimization was explained by genetic factors, with the remainder due to environmental factors not shared by twins. Based on the same sample but combining age 10 and age 7 reports, Bowes et al. (2013) confirmed the estimates for peer victimization in primary school $(71 \%$ of the variance being due to genetic factors) and reported an even higher estimate (77\%) for victimization at age 12 . Very much in line with those estimates, Connolly and Beaver (2016) found $70 \%$ of the variance in childhood victimization recalled at age 12 to be due to genetic factors and $30 \%$ due to non-shared environmental factors in the NLSY97 sample. Lower heritability estimates were found by Brendgen et al. (2011), who used peer nominations of victimization for over 200 twin children. Their study suggests that most of the variance in victimization is due to non-shared environmental factors and measurement error $(78 \%)$ and only a small portion is due to genetic factors (21\%). None of these studies found evidence for a shared environmental contribution, in contrast to Boivin et al. (2013), who reported that $26 \%$ of the variance in teacher-reported victimization among almost 900 twin children was due to shared environmental factors. In balance, genetic and non-shared environmental influence on bullying and victimization was present in most studies but estimates varied.

\section{Peer Victimization and Maladjustment}

Non-genetic studies usually imply that peer victimization contributes to maladjustment risk. There is considerable empirical support that victimized youths are at elevated risk for internalizing problems, such as anxiety (Storch et al., 2005; Zwierzynska et al., 2013), suicidal ideation (Winsper et al. 2012), and depression (Hawker \& Boulton 2000; Kretschmer et al., 2014; Reijntjes et al., 2010; Ttofi et al., 2011). However, internalizing problems are also heritable: genetic factors explain approximately $30-40 \%$ of the variance in internalizing problems (Lau \& Eley, 2010). This prompts the question whether associations between peer victimization and internalizing symptoms are indeed causal - meaning that peer victimization poses a unique risk for internalizing problems - or whether common genetic vulnerability predicts both peer victimization and internalizing problems. The latter pattern, where common genetic sources influence different phenotypes, has been termed 'pleiotropy' and constitutes an important alternative explanation to phenotypic causation.
Bivariate twin models are useful to tackle this question because they provide estimates of genetic and environmental covariance between two phenotypes (e.g., victimization and depression). Brendgen and colleagues (2009) showed that over $50 \%$ of the variance in young children's depressive behavior was associated with genetic factors that also influenced peer rejection - another source of potentially pervasive peer stress that tends to precede peer victimization - suggesting that the genetic risk for children to be exposed to peer rejection also increased the risk for depression. Connolly and Beaver (2016) also found genetic and non-shared environmental factors explaining the association between victimization in childhood and a composite of measures of depression and anxiety taken between 3 and 13 years later. Similar results were reported for peer victimization and other internalizing phenotypes, such as adolescent anxiety (Brendgen et al., 2015) and paranoid thinking in adolescence (Shakoor et al. 2015).

\section{Current Study}

Previous studies find phenotypic as well as genetic correlations between victimization and internalizing problems. However, from this, we cannot conclude whether victimization indeed poses a unique risk for maladjustment or whether common genetic factors explain this association. Most central to our study is the question whether genes are a common cause for both victimization and depression (pleiotropy), or whether genetic influences on one phenotype are mediated by the causal effect of the other.

In order to shed light on this question, we employed data from a large sample of identical and non-identical adult female twins from the TwinsUK registry who retrospectively reported on peer victimization in school and completed self-reports of depressive episodes in the past year. In line with other genetically sensitive studies, we first examined shared and non-shared environmental factors, expecting significant genetic contributions to both.

We calculated the extent to which individual differences in peer victimization and depressive episodes in the past year, as well as any covariation between both measures, was due to genetic and environmental factors using conventional Cholesky decomposition models that estimate additive genetic (A), shared environmental (C), and non-shared environmental influences (E, including measurement error; D'Onofrio et al., 2013). While these uni- and bivariate ACE models shed light on genetic and/or environmental contributions to variance in traits and covariance between two traits, they do not inform about the potential causal relation between the traits.

To tackle this problem, we also applied an extension of the ACE model - the so-called ACE- $\beta$ model (Kohler et al., 2011) - which integrates the estimate from a withinidentical twin model into the model to establish a causal 
link between both outcomes and simultaneously corrects the genetic and shared environmental correlations for this causal effect. Consequently, the contributions of the latent factors may be interpreted as common causes for the observed associations, defined as pleiotropy for shared genetic effects.

\section{Method}

\section{Sample}

Data for this study came from identical and non-identical twins who participated in surveys of the TwinsUK registry. Involving more than 12,000 individuals, TwinsUK represents the largest adult twin registry in the United Kingdom. Extensive information on data collection procedures and sample characteristics has been provided elsewhere (Moayyeri et al., 2013). As part of the assessment in 2002, $n=5,096$ participants completed retrospective information on bullying perpetration and victimization. Because participants were on average 60 years old, we can assume that they had finished school more than 40 years prior to reporting on their bullying-victimization experience. Of these, $n=$ 3,791 participants reported on past year prevalence of depression in the year 2000 assessment. The registry consists mainly of women $(87 \%)$; to avoid unnecessary heterogeneity, we excluded $n=340$ male participants from the analysis, as well as $n=6$ individuals with missing zygosity information, $n=13$ reared-apart twins, and $n=922$ singletons. For conventional univariate and bivariate ACE models, we thus relied on data from $n=2,510$ females, of which $48 \%$ were non-identical twins $(n=1,214)$ and $52 \%$ were identical twins $(n=1,296)$. Only data from identical twins were used in the ACE- $\beta$ model.

\section{Measures}

The variables of interest to this study were peer victimization, and whether an individual had experienced depressive episodes in the past year. Depressive episodes were assessed when twins were on average 58 years old (assessment in 2000) using the Twins Health Questionnaire, developed for the TwinsUK study, which asked respondents to indicate how often in the past year they had experienced various health-related symptoms or received diagnoses, referring to allergies, immune system and respiratory problems, gastrointestinal and cardiovascular diseases, reproductive health, behavioral risk factors, as well as psychological symptoms. As such, the depressive episodes measure used in this study was obtained via self-report (How often did you get depressed in the last year?) and does not constitute a clinical diagnosis.

Peer victimization was assessed retrospectively when twins were on average 60 years old (assessment in 2002) using one item (While at school, were you ever bullied?) and measured on a scale ranging from $0=$ never to $4=$ always.

\section{Analytic Strategy}

In order to quantify genetic and environmental influences on each phenotype, we applied univariate ACE models in a structural equation framework to decompose the observed variance in peer victimization and depressive episodes into variance associated with additive genetic effects (A), the shared environment of twins $(\mathrm{C})$, and the non-shared environment of twins (E; see Neale \& Cardon 1992). E is also assumed to contain random measurement error. We assessed the significance of each variance component via likelihoodratio tests where the full ACE model is tested against more parsimonious models, with variance components set to 0 one after another.

Second, we examined shared genetic and environmental contributions to covariance between peer victimization and depressive episodes using bivariate models. Specifically, we applied a bivariate ACE model (Loehlin, 1996; Neale \& Cardon, 1992; see Figure 1(a)) where we introduced depressive episodes with its own genetic and environmental endowment to the peer victimization model and allowed the latent factors of peer victimization to influence depressive episodes. This procedure allowed us to evaluate to what extent additive genetic, shared environmental, and nonshared environmental effects for peer victimization are also associated with variation in depressive episodes.

Next, we integrated a direct effect of peer victimization on depressive episodes into the model to evaluate simultaneously (a) the causal effect of victimization on depressive episodes and (b) whether genetic and shared environmental influences across phenotypes can be interpreted as common causes and are thus independent of phenotypic mediation (see Figure 1(b)).

To estimate the causal effect of victimization, we computed within-identical twin models (for a recent introduction and discussion of this method, see Amin et al., 2015; Boardman \& Fletcher, 2015). Similar to experimental and quasi-experimental designs, which use exogenous variation to randomize treatment and control groups post-hoc, within-twin designs offer an approach to testing causality. The within-twin approach controls for all factors shared among siblings, including genetic material, by using identical twins as a natural experiment (Kohler et al., 2011). Twins differ in levels of victimization, but neither in their genetic make-up nor their family environment. Kohler and colleagues (2011) proposed a model that integrates the withinidentical twin estimate as a causal effect $(\beta)$ into the ACE model (see Figure 1(b)). A bivariate ACE model including a direct effect of one observed trait on the other is no longer identifiable. Therefore, we make the identifying assumption that path $e_{12}$ in Figure 1(a) is zero (Kohler et al.). This assumption is plausible, as it implies that the non-shared environmental factor $(\mathrm{E})$ that explains variance in peer victimization only predicts depressive episodes through its effect on peer victimization, but not directly (see also the section 'Discussion'). Using this strategy, we can estimate a causal 
Figure 1(a) ACE model

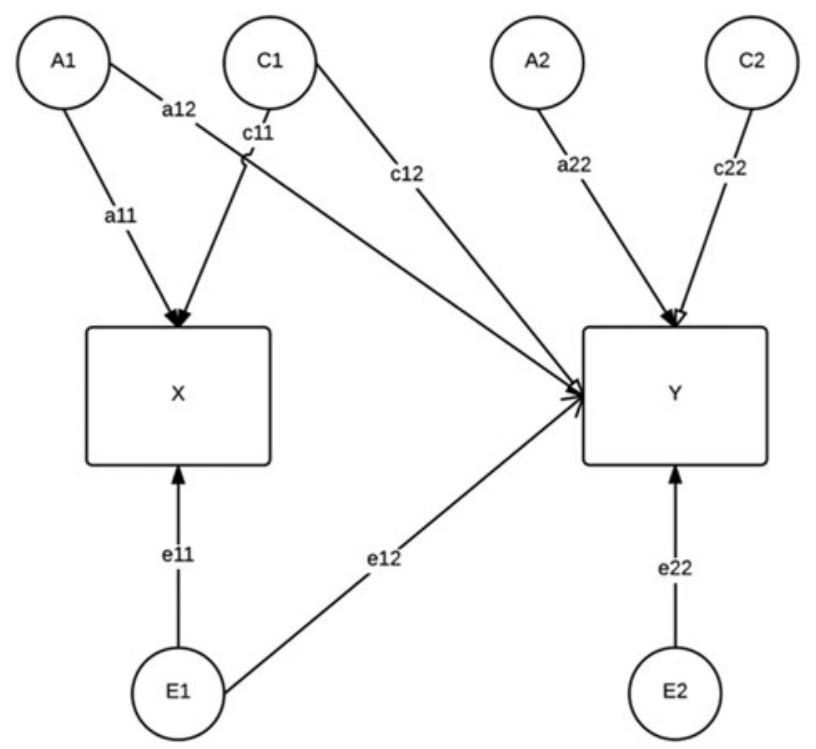

Figure 1(b) ACE- $\beta$ model

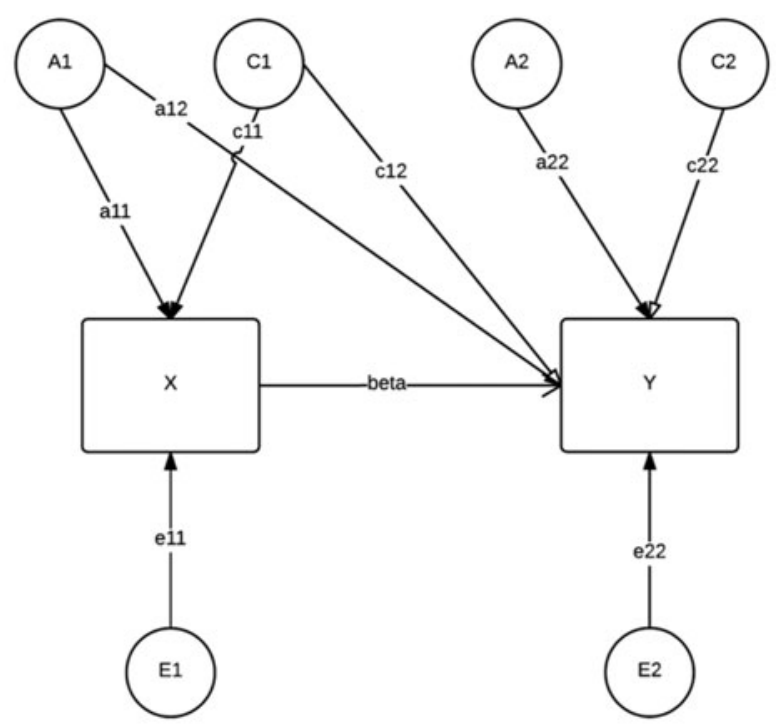

\section{FIGURE 1}

Schematic (a) ACE model and (b) ACE- $\beta$ model introducing a causal pathway between phenotypes.

$\mathrm{A} 1$ = genetic factor for $\mathrm{X}, \mathrm{A} 2=$ genetic factor unique to $\mathrm{Y}, \mathrm{C} 1=$ common environmental factors for $\mathrm{X}, \mathrm{C} 2=$ common environmental factors unique to $\mathrm{Y}, \mathrm{E} 1=$ non-shared environmental factors $\mathrm{X}, \mathrm{E} 2=$ non-shared environmental factor unique to $\mathrm{Y}, \beta=$ causal effect of $\mathrm{X}$ on $\mathrm{Y}$.

effect in a regression model. Comparing the ACE model and the ACE- $\beta$ model therefore also gives insights into what extent, for example, the genetic correlation between two outcomes is phenotypically mediated and to what extent the genetic correlation represents pleiotropy. All models control for birth year of the twins.

\section{Results}

\section{Descriptive Statistics}

Table 1 depicts all descriptive statistics. Most participants had not been victimized during their school years $(62 \%)$ but $38 \%$ confirmed experiences of peer victimization. Approximately $60 \%$ of participants did not report any depressive episodes in the past year, approximately $23 \%$ reported one episode, $9 \%$ reported two episodes, $5 \%$ reported three episodes, and $3 \%$ reported four depressive episodes. The average number of depressive episodes in our sample was less than one (0.7).

At least two conditions had to be met for subsequent models: (1) to motivate the bivariate behavior genetics analysis, a correlation between both phenotypes was necessary. The correlation between peer victimization and depressive episodes was $r=0.22, p<.001$. This overlap allows for a closer inspection of the underlying forces of this relationship. (2) For the within-identical twin pair analysis, (sufficient) within identical-twin pair variation in the constructs under investigation - particularly in the independent variable - is crucial to enable detection of a causal effect. Within-identical twin pair differences in peer victimization and depression were 0.51 and 0.71 , thus around half of the variation in peer victimization remains within MZ, suggesting sufficient variation for our modeling approach.

\section{Univariate Models}

We applied a model-fitting approach (Neale \& Cardon, 1992) to infer the best fitting yet parsimonious model within the ACE framework (see Supplementary Material Table S1 for all model fit statistics). For both phenotypes, shared environmental effects were non-significant and could be dropped from the model without loss in fit. Standardized estimates derived from the resulting univariate $\mathrm{AE}$ models were largely in line with previous findings (see Table 2). In detail, $45 \%$ of the variance in retrospective self-reports of peer victimization during adolescence and $30 \%$ of the variance in number of depressive episodes in the past year were associated with additive genetic, with the remainder being due to non-shared environmental influences and measurement error.

\section{Bivariate Models}

To examine whether peer victimization and depressive episodes were associated because of common environmental and/or genetic factors or whether peer victimization causally led to later depressive episodes, we estimated bivariate ACE (Boker et al., 2011) and ACE- $\beta$ models (Kohler et al., 2011). Given that the common environmental component (C) had no significant effect either on peer 
TABLE 1

Descriptive Statistics for Female UK Twins Born Between 1919 and 1982 ( $N=2,510,48 \%$ DZ)

\begin{tabular}{|c|c|c|c|c|c|c|c|}
\hline \multirow[b]{3}{*}{ Age } & & \multicolumn{3}{|c|}{$M Z$} & \multicolumn{3}{|c|}{ DZ } \\
\hline & & \multirow{2}{*}{\begin{tabular}{l}
\multicolumn{1}{c}{ Mean $(S D)$} \\
$59.78(12.93)$ \\
Count
\end{tabular}} & \multicolumn{2}{|c|}{ Min-Max } & \multirow{2}{*}{$\begin{array}{l}\text { Mean (SD) } \\
60.56(11.40) \\
\text { Count }\end{array}$} & \multicolumn{2}{|c|}{ Min-Max } \\
\hline & & & $\begin{array}{l}26 \\
\text { Cum }\end{array}$ & $\begin{array}{c}85 \\
\text { ated (\%) }\end{array}$ & & $\begin{array}{l}25 \\
\text { Cun }\end{array}$ & $\begin{array}{l}89 \\
\text { ulated (\%) }\end{array}$ \\
\hline Depression $^{a}$ & $\begin{array}{l}0 \\
1 \\
2 \\
3 \\
4\end{array}$ & $\begin{array}{l}770 \\
307 \\
118 \\
60 \\
41 \\
\text { Mean (SD) }\end{array}$ & $\begin{array}{r}59.4 \\
83.1 \\
92.2 \\
96.8 \\
100 . \\
\mathrm{M}\end{array}$ & -Max & $\begin{array}{l}701 \\
303 \\
112 \\
77 \\
21 \\
\text { Mean (SD) }\end{array}$ & $\begin{array}{r}57.7 \\
82.7 \\
91.9 \\
98.2 \\
100 \\
N\end{array}$ & n-Max \\
\hline $\begin{array}{l}\text { Summary } \\
\text { Within twin-pair differences } \\
\text { Intraclass correlation }\end{array}$ & & $\begin{array}{l}0.68(1.03) \\
0.71(0.96) \\
\text { Coefficient } \\
0.33\end{array}$ & $\begin{array}{l}0 \\
0 \\
S E \\
0.04\end{array}$ & $\begin{array}{l}4 \\
4\end{array}$ & $\begin{array}{l}0.70(0.99) \\
0.85(1.00) \\
\text { Coefficient } \\
0.13\end{array}$ & $\begin{array}{l}0 \\
0 \\
S E \\
0.04\end{array}$ & $\begin{array}{l}4 \\
4\end{array}$ \\
\hline Victimized & $\begin{array}{l}\text { Never } \\
\text { Rarely } \\
\text { Sometimes } \\
\text { Often } \\
\text { Always }\end{array}$ & $\begin{array}{l}\text { Count } \\
793 \\
223 \\
228 \\
44 \\
8 \\
\text { Mean (SD) }\end{array}$ & $\begin{array}{r}\text { Cum } \\
61.1 \\
78.4 \\
95.9 \\
99.3 \\
100 . \\
\mathrm{M}\end{array}$ & $\begin{array}{l}\text { ated (\%) } \\
\text {-Max }\end{array}$ & $\begin{array}{l}\text { Count } \\
771 \\
234 \\
177 \\
28 \\
4 \\
\text { Mean (SD) }\end{array}$ & $\begin{array}{r}\text { Cun } \\
63.5 \\
82.7 \\
97 . \\
99 . \\
100 \\
1\end{array}$ & $\begin{array}{l}\text { ulated (\%) } \\
\text { n-Max }\end{array}$ \\
\hline $\begin{array}{l}\text { Summary } \\
\text { Within twin-pair differences } \\
\text { Intraclass correlation }\end{array}$ & & $\begin{array}{l}1.65(0.93) \\
0.51(0.74) \\
\text { Coefficient } \\
0.53\end{array}$ & $\begin{array}{l}0 \\
0 \\
S E \\
0.03\end{array}$ & $\begin{array}{l}4 \\
3\end{array}$ & $\begin{array}{l}1.57(0.85) \\
0.69(0.85) \\
\text { Coefficient } \\
0.17\end{array}$ & $\begin{array}{l}0 \\
0 \\
S E \\
0.0\end{array}$ & $\begin{array}{l}4 \\
4\end{array}$ \\
\hline $\begin{array}{l}N \\
N \text { total }\end{array}$ & & & & & & & \\
\hline
\end{tabular}

Note: ${ }^{a}$ Depressive episodes in the last 12 months.

TABLE 2

Univariate Twin Models Describing Decomposition of the Observed Variance in Depression and Victimization Into Additive Genetic Effects and Non-Shared Environmental Effects

\begin{tabular}{llll}
\hline & Heritability & $95 \% \mathrm{Cl}$ & $\begin{array}{c}\text { Non-shared } \\
\text { environment }\end{array}$ \\
\hline $\begin{array}{l}\text { Depression } \\
\text { Victimization }\end{array}$ & 0.30 & $0.24-0.36$ & 0.70 \\
\hline Note: We followed a model-fitting approach considering all possible models of the ACE variance components: additive genetic effects, \\
shared environmental effects, unique environmental effects (see Table S1). For both phenotypes, the AE models (A = additive \\
genetic effects; E = non-shared environmental effects) showed the best-fit model. a Depressive episodes in the last 12 month.
\end{tabular}

victimization or depressive episodes in univariate models, we omitted $\mathrm{C}$ from the bivariate models.

The bivariate AE (Figure 2(a)) model showed that genetic factors underlying peer victimization were also significantly associated with depression $(0.20, S E=0.04)$. Moreover, non-shared environmental effects for victimization showed a significant effect on depression $(0.09, S E=0.03)$.

We next decomposed the observed association between both measures into genetic and environmental associations by dividing the genetic covariance $a_{11} \times a_{12}$ by the overall covariance $a_{11} \times a_{12}+e_{11} \times e_{12}$. Following this, $\sim 68 \%$ (= $0.57 \times 0.20 /[0.57 \times 0.20+0.64 \times 0.09] \times 100)$ of the association between victimization and depressive episodes was associated with shared genetic effects between both measures. The remaining $32 \%$ of the covariation between victimization and depressive episodes was explained by nonshared environmental factors common to both phenotypes.
The non-shared environmental covariation between victimization and depressive episodes may in be interpreted as a quasi-causal effect of victimization on depressive episodes (D'Onofrio et al., 2013). However, the classic modeling approach interprets this covariance as independent of the genetic covariance, while a causal link between both phenotypes would lead to a genetic covariance in the case that victimization is genetically influenced. The ACE- $\beta$ model (Figure 2(b)) therefore integrates the direct effect between both phenotypes, so that the genetic covariation may be interpreted as pleiotropic.

As expected, we found a statistically significant effect of peer victimization on adult depressive episodes from the within-identical twin model $(0.13, S E=0.05)$. This implies that the genetic correlation between victimization and depressive episodes might not represent pleiotropic effects alone and that shared genetic effects might be 
Figure 2(a) AE-model

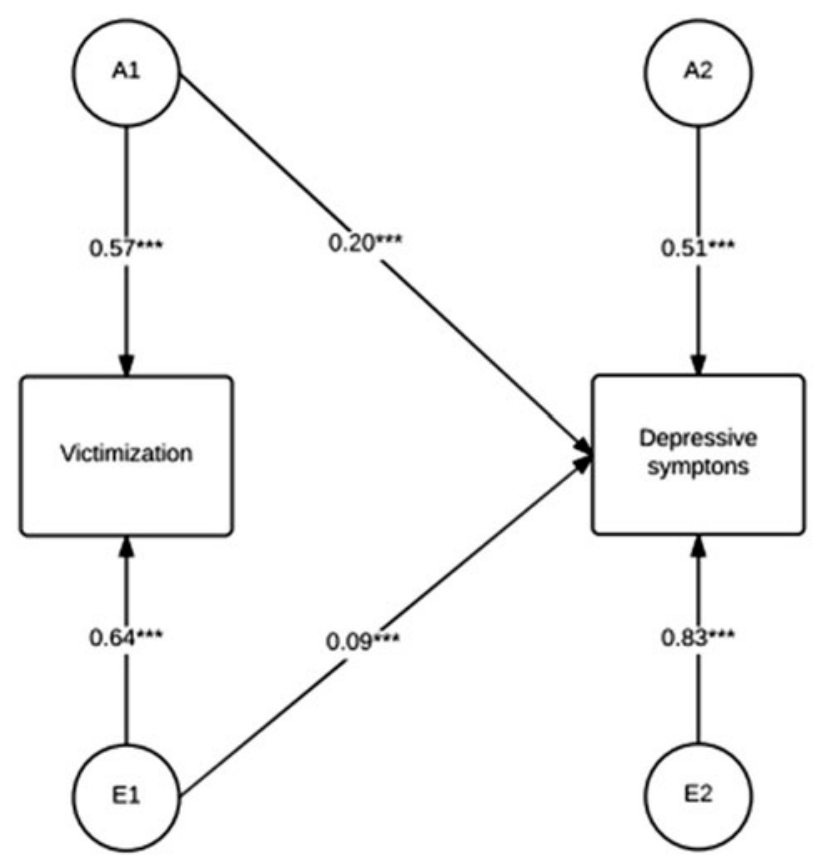

Figure 2(b) AE- $\beta$ model

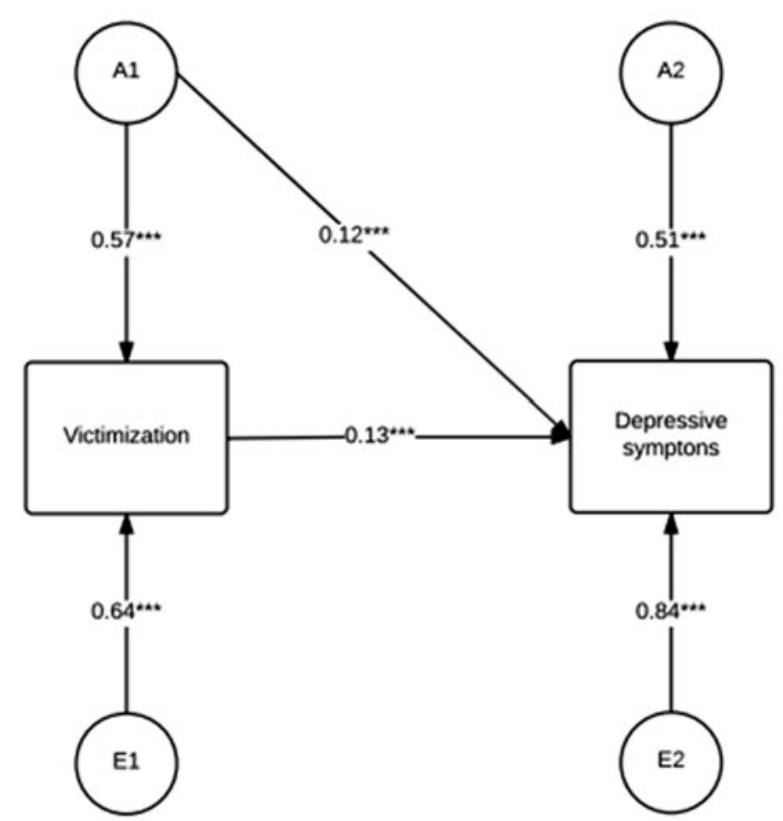

FIGURE 2

Bivariate genetic models ((a) ACE model and (b) ACE- $\beta$ model) on victimization and depression for female UK twins born between 1919 and 1982 ( $N=2,510,48 \% \mathrm{DZ})$. A1 = genetic factor for victimization, $A 2=$ genetic factor unique to depression, E1 = non-shared environmental factors victimization, E2 = non-shared environmental factor unique to depression.

phenotypically mediated by a causal effect of victimization on depressive episodes. Indeed, when comparing Figure 2(a) and 2(b), the genetic overlap between peer victimization and depressive episodes decreased by approximately $40 \%$ from 0.20 to $0.12(S E=0.06)$, while remaining significantly different from zero. If we calculate the contribution of genes to the observed association in the ACE- $\beta$ model, which includes a direct effect between the phenotypes, we observe reduction. In this model, the overall covariance is $\beta \sigma^{2}\left(X_{i j}\right)+a_{x x} a_{y x}$ and genetic factors account for $\sim 42 \%\left(=\left(0.57 \times 0.12 /\left[0.57 \times 0.12+0.13 \times\left(0.64^{2}+0.57^{2}\right)\right]\right.\right.$ $\times 100$ ) of the observed variation, while the causal effect accounts for the remaining $58 \%$. Therefore, around half of the association between victimization and depressive episodes can be attributed to pleiotropic effects in this model.

\section{Discussion}

The central aim of this study was to identify to what extent genetic and environmental factors are responsible for the association between peer victimization and depressive episodes and whether victimization might function as causal influence on depressive episodes. The latter pattern is often implied in interpretations of cross-sectional and longitudinal studies, but experimental designs or quasiexperimental designs - as in the case for twins - are needed to elucidate whether effects of peer victimization on maladjustment may represent two 'outcomes' of common underlying genetic factors. We were fortunate to use data from over 2,500 adult twins whose retrospective reports of peer victimization spanned their entire time at school. The data on depressive episodes referred to a recent period. The number of male twins who had completed these assessments was low, which means that our results are based on female twins only.

Overall, univariate models confirmed important roles for genetic and non-shared environmental sources of variance both for depressive episodes as well as for peer victimization. The genetic contribution to peer victimization in our sample was somewhat lower than found in some other studies (Ball et al., 2008; Brendgen et al., 2011) but in keeping with studies that also used self-reports (Boivin et al., 2013). It is possible that the retrospective nature of our peer victimization report influenced the pattern of results somewhat. However, it is notable that despite differences in assessments, our findings largely correspond to other studies.

The overlap between peer victimization and depressive episodes was substantially associated with shared genetic effects across phenotypes, which is in line with prior research (Brendgen et al., 2009). It is possible that genetic sources of variance are particularly important in explaining the overlap between retrospective reports or memories of victimization and depression. For instance, individuals who are genetically more prone for depression might recall 
experiences of victimization even if their occurrence dates back several decades.

The most innovative contribution of the current study is methodological in that we applied a novel behavior genetic approach to establishing causality in the absence of experimental data (Kohler et al., 2011) and indeed detected an effect of victimization on depressive episodes when controlling for factors shared among genetically identical twins who have been raised in the same family. This direct contribution of victimization to mental health is in line with a recent study using the Twins Early Development Study (TEDS) sample that employed an MZ difference design, where the difference between monozygotic twins in an outcome measure (e.g., d epression) was regressed on the difference in exposure (here, victimization) and found that victimization in childhood contributed to mental health problems in adolescence (Singham et al., 2017).

While these findings underline the importance of preand intervention programs that reduce victimization prevalence as those programs might indeed have an important effect on improvement of mental health of individuals, it should be kept in mind that even when we control for the causal effect, around $40 \%$ of the observed association between victimization and depressive episodes was associated with shared genetic effects, interpretable as common causes for the association (i.e., pleiotropy). This finding is suggestive of an underlying genetic vulnerability to exposure to environmental risk as well as mental health difficulties and implies that even when peer victimization can be reduced, the risk for depressive episodes remains to some extent, because this risk is independent of the causal link between both phenotypes.

Despite the strength of the approach used here, it is important to unpack some model assumptions and limitations of this study to warrant valid interpretation and clarify the future research opportunities. First, the withinidentical twin approach comes at the cost of the assumption that individual differences in victimization within-twin pairs are uncorrelated with individual differences in depressive episodes. The question is, therefore, why is one twin victimized and the other is not? If, for example, an individual experience of one of the twins would lead to victimization and also to internalizing problems, then the true causal effect would be smaller than estimated from the withinidentical twin model. The direction and magnitude of such a bias remains unknown. Additionally, measurement error can downwardly bias the estimates (see for a discussion, Amin et al., 2013). Alternative designs to validate our findings are quasi-experimental studies that use exogenous variance (instrument variables) to post-hoc randomize victims (these designs are also not without their limitations; for a recent discussion see Amin et al., 2015; Boardman \& Fletcher, 2015).

Second, it might be that individuals who are prone to depressive episodes are also at greater risk for peer victim- ization; for example, because they react more strongly to provocation by others, are biased in their attributions towards social interactions, or are simply more vulnerable due to depressive symptoms, such as withdrawal behavior already present. In this scenario, additive genetic effects for victimization are partly mediated by genetically influenced individual differences in internalizing symptoms. Longitudinal studies in which depression is assessed prior to any peer victimization may give a clearer assessment of the temporal succession of both processes. Moreover, longitudinal modeling can be combined with twin as well as molecular genetic data; for instance, one might utilize polygenic risk scores. Adequate data sources for those approaches, however, are scarce.

Third, our measure of depressive episodes was obtained using self-reports and referred to the past year only. While such a quantitative measure allowed for the analyses presented here, we were not able to support our conclusions with clinical diagnoses or explore whether peer victimization contributes to recurrent depressive episodes covering a longer time span. Moreover, more than one in three women reported at least one episode, which is suggestive of respondents understanding this measure more as an assessment of mood than clinical disorder.

Fourth, victimization measured using self-report might be confounded by individual differences that are associated with internalizing problems, namely, that individuals with a higher disposition for internalizing problems are more likely to report negative peer experiences than other individuals. Particularly the assessment in adulthood might be biased so that more internalizing individuals, for example, ruminate more about negative childhood experiences or rationalize depressive episodes post-hoc, based on earlier interpersonal experiences.

Fifth, the time difference of approximately 40 years between exposure to peer victimization and assessment thereof might have induced recall bias and led to inaccurate reporting. However, we are confident that particularly traumatizing experiences of victimization - those that were chronic and shaped respondents' subsequent interpersonal and psychological development - were more likely to be recalled, whereas experiences that were less meaningful for development were more likely to be forgotten. This reasoning also applies to the absence of a clear definition of bullying provided to respondents. While its inclusion has been promoted in bullying research, this is particularly important in prospective child samples and intervention studies, where selecting victimized children for further assessment and treatment relies on a shared and clear understanding of the problem at hand. In this study, however, we were interested in the longitudinal link with depressive episodes; respondents own perceptions that what they had experienced was bullying thus stood central. Related, we were not able to distinguish between victimization that happened once or twice and more chronic forms. That is, whether or not 
adverse experiences like victimization are stable occurrences across childhood is likely to affect strength and stability of associations with maladjustment and inclusion of this information can further improve study designs as used here.

Finally, behavior genetic models typically make a series of assumptions, such as no assortative mating and absence of gene-environment interactions (Kohler et al., 2011), which require further investigation. Additionally, in the raw data, we observed a relatively high correlation for monozygotic twins in respect of victimization $(0.53$, see Table 1 ) compared to dizygotic twins (0.17), suggesting potential gene-environment interaction or dominant genetic effects important for victimization. In the same vein, the residual genetic correlation in the ACE- $\beta$ model can be interpreted as genetic common cause (pleiotropy) for victimization and depressive symptoms. Large-scale molecular genetic data that include childhood experiences, such as victimization, would help to further elucidate the share genetic etiology of both traits.

The noted limitations were inevitable in our use of archived data and application of a particular modeling approach. Such models and data, however, are of immense value to understand long-term associations between interpersonal experiences and outcomes later in life. That is, the particular strength of our study lies in its demonstration of how longitudinal twin samples can be utilized to shed light on causal processes. To conclude, we encourage genetically informed research on peer victimization, its antecedents and correlates, ideally including longitudinal phenotypic measures as well as molecular genetic data. Interpersonal experiences should not be seen in 'environmental isolation', as our findings show the importance of integrating genetic information into social science research.

\section{Supplementary material}

To view supplementary material for this article, please visit https://doi.org/10.1017/thg.2017.71

\section{References}

Amin, V., Behrman, J. R., \& Spector, T. D. (2013). Does more schooling improve health outcomes and health related behaviors? Evidence from UK twins. Economics of Education Review, 35, 134-148.

Amin, V., Behrman, J. R., Kohler, H.-P., Xiong, Y., \& Zhang, J. (2015). Causal inferences: Identical twins help and clarity about necessary assumptions is critical. Social Science \& Medicine, 127, 201-202.

Arseneault, L., Milne, B. J., Taylor, A., Adams, F., Delgado, K., Caspi, A., \& Moffitt, T. E. (2008). Being bullied as an environmentally mediated contributing factor to children's internalizing problems: A study of twins discordant for victimization. Archives of Pediatrics \& Adolescent Medicine, $162,145-150$.
Ball, H. A., Arseneault, L., Taylor, A., Maughan, B., Caspi, A., \& Moffitt, T. E. (2008). Genetic and environmental influences on victims, bullies and bully-victims in childhood. Journal of Child Psychology and Psychiatry, 49, 104-112.

Boardman, J. D., \& Fletcher, J. M. (2015). To cause or not to cause? That is the question, but identical twins might not have all of the answers. Social Science \& Medicine, 127, 198200.

Boivin, M., Brendgen, M., Vitaro, F., Dionne, G., Girard, A., Pérusse, D., \& Tremblay, R. E. (2013). Strong genetic contribution to peer relationship difficulties at school entry: Findings from a longitudinal twin study. Child Development, 84 , 1098-1114.

Boker, S., Neale, M., Maes, H., Wilde, M., Spiegel, M., Brick, T., ... Bates, T. (2011). OpenMx: An open source extended structural equation modeling framework. Psychometrika, 76, 306-317.

Bowes, L., Maughan, B., Ball, H., Shakoor, S., Ouellet-Morin, I., Caspi, A., ... Arseneault, L. (2013). Chronic bullying victimization across school transitions: The role of genetic and environmental influences. Development and Psychopathology, 25, 333-346.

Brendgen, M., Boivin, M., Dionne, G., Barker, E. D., Vitaro, F., Girard, A., ... Perusse, D. (2011). Gene-environment processes linking aggression, peer victimization, and the teacher-child relationship. Child Development, 82, 20212036.

Brendgen, M., Girard, A., Vitaro, F., Dionne, G., \& Boivin, M. (2015). The dark side of friends: A genetically informed study of victimization within early adolescents' friendships. Journal of Clinical Child \& Adolescent Psychology, 44, 417431.

Brendgen, M., Vitaro, F., Boivin, M., Girard, A., Bukowski, W. M., Dionne, G., .. Pérusse, D. (2009). Geneenvironment interplay between peer rejection and depressive behavior in children. Journal of Child Psychology and Psychiatry, 50, 1009-1017.

Connolly, E. J., \& Beaver, K. M. (2016). Considering the genetic and environmental overlap between bullying victimization, delinquency, and symptoms of depression/anxiety. Journal of Interpersonal Violence, 31, 1230-1256.

Copeland, W. E., Wolke, D., Angold, A., \& Costello, E. J. (2013). Adult psychiatric outcomes of bullying and being bullied by peers in childhood and adolescence. JAMA Psychiatry, 70, 419-426.

D’Onofrio, B. M., Lahey, B. B., Turkheimer, E., \& Lichtenstein, P. (2013). Critical need for family-based, quasiexperimental designs in integrating genetic and social science research. American Journal of Public Health, 103, S46-S55.

Hawker, D. S., \& Boulton, M. J. (2000). Twenty years' research on peer victimization and psychosocial maladjustment: A meta-analytic review of cross-sectional studies. Journal of Child Psychology and Psychiatry, 41, 441-455.

Kohler, H.-P., Behrman, J. R., \& Schnittker, J. (2011). Social science methods for twins data: Integrating causality, endowments, and heritability. Biodemography and Social Biology, 57, 88-141. 
Kretschmer, T., Barker, E. D., Dijkstra, J. K., Oldehinkel, A. J., \& Veenstra, R. (2014). Multifinality of peer victimization: Maladjustment patterns and transitions from early to midadolescence. European Child \& Adolescent Psychiatry, 24, 1169-1179.

Lau, J. Y., \& Eley, T. C. (2010). The genetics of mood disorders. Annual Review of Clinical Psychology, 6, 313-337.

Loehlin, J. C. (1996). The Cholesky approach: A cautionary note. Behavior Genetics, 26, 65-69.

Moayyeri, A., Hammond, C., \& Spector, T. D. (2013). Cohort profile: TwinsUK and healthy ageing twin study. International Journal of Epidemiology, 42, 76-85.

Nansel, T. R., Overpeck, M., Pilla, R. S., Ruan, W. J., SimonsMorton, B., \& Scheidt, P. (2001). Bullying behaviors among US youth. Journal of the American Medical Association, 285, 2094-2100.

Neale, M. C., \& Cardon, L. R. (1992). Methodology for genetic studies of twins and families. Dordrecht, the Netherlands: Kluwer Academic Publishers.

Olweus, D. (1993). Victimization by peers: Antecedents and long-term outcomes. In K. H. Rubin \& J. B. Asendorpf (Eds.), Social withdrawal, inhibition, and shyness in childhood (pp. 315-341). Mahwah, NJ: Erlbaum.

Reijntjes, A., Kamphuis, J. H., Prinzie, P., \& Telch, M. J. (2010). Peer victimization and internalizing problems in children: A meta-analysis of longitudinal studies. Child Abuse \& $\mathrm{Ne}$ glect, 34, 244-252.

Schreier, A., Wolke, D., Thomas, K., Horwood, J., Hollis, C., Gunnell, D., ... Duffy, L. (2009). Prospective study of peer victimization in childhood and psychotic symptoms in a nonclinical population at age 12 years. Archives of General Psychiatry, 66, 527-536.

Shakoor, S., McGuire, P., Cardno, A. G., Freeman, D., Plomin, R., \& Ronald, A. (2015). A shared genetic propensity underlies experiences of bullying victimization in late childhood and self-rated paranoid thinking in adolescence. Schizophrenia Bulletin, 41, 754-763.

Singham, T., Viding, E., Schoeler, T., Arseneault, L., Ronald, A., Cecil, C. M., ... Pingault, J.-B. (2017). Concurrent and longitudinal contribution of exposure to bullying in childhood to mental health: The role of vulnerability and resilience. JAMA Psychiatry, 74, 1112-1119.

Storch, E. A., Masia-Warner, C., Crisp, H., \& Klein, R. G. (2005). Peer victimization and social anxiety in adolescence: A prospective study. Aggressive Behavior, 31, 437452.

Takizawa, R., Maughan, B., \& Arseneault, L. (2014). Adult health outcomes of childhood bullying victimization: Evidence from a five-decade longitudinal British birth cohort. American Journal of Psychiatry, 171, 777-784.

Ttofi, M. M., Farrington, D. P., Lösel, F., \& Loeber, R. (2011). Do the victims of school bullies tend to become depressed later in life? A systematic review and meta-analysis of longitudinal studies. Journal of Aggression, Conflict and Peace Research, 3, 63-73.

Winsper, C., Lereya, T., Zanarini, M., \& Wolke, D. (2012). Involvement in bullying and suicide-related behavior at 11 years: A prospective birth cohort study. Journal of the American Academy of Child \& Adolescent Psychiatry, 51, 271282.

Wolke, D., Copeland, W. E., Angold, A., \& Costello, E. J. (2013). Impact of bullying in childhood on adult health, wealth, crime, and social outcomes. Psychological Science, 24, 1958-1970.

Zwierzynska, K., Wolke, D., \& Lereya, T. S. (2013). Peer victimization in childhood and internalizing problems in adolescence: A prospective longitudinal study. Journal of Abnormal Child Psychology, 41, 309-323. 